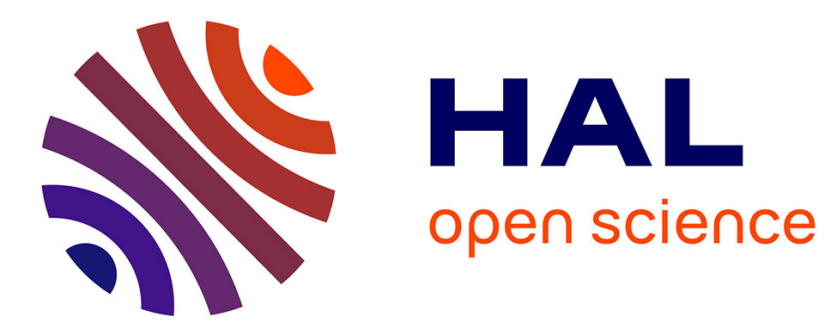

\title{
X-ray reflectivity study of the structure of cadmium stearate and cadmium behenate Langmuir-Blodgett films with a small amount of layers
}

\author{
O. Konovalov, L. Feigin
}

\section{- To cite this version:}

O. Konovalov, L. Feigin. X-ray reflectivity study of the structure of cadmium stearate and cadmium behenate Langmuir-Blodgett films with a small amount of layers. Journal de Physique IV Proceedings, 1993, 03 (C8), pp.C8-185-C8-188. 10.1051/jp4:1993837 . jpa-00252268

\section{HAL Id: jpa-00252268 https://hal.science/jpa-00252268}

Submitted on 1 Jan 1993

HAL is a multi-disciplinary open access archive for the deposit and dissemination of scientific research documents, whether they are published or not. The documents may come from teaching and research institutions in France or abroad, or from public or private research centers.
L'archive ouverte pluridisciplinaire HAL, est destinée au dépôt et à la diffusion de documents scientifiques de niveau recherche, publiés ou non, émanant des établissements d'enseignement et de recherche français ou étrangers, des laboratoires publics ou privés. 


\title{
$X$-ray reflectivity study of the structure of cadmium stearate and cadmium behenate Langmuir-Blodgett films with a small amount of layers
}

\author{
O.V. KONOVALOV and L.A. FEIGIN
}

Institute of Crystallography, Russian Academy of Sciences, 117333 Moscow, Russia

\begin{abstract}
Structure of a thin cadmium stearate and cadmium behenate Langmuir - Blodgett films are studied using X-ray reflectivity techniqie. Difference in the structure of interfacial and bulk monolayers are found and described. The uppest and the lowest Langmuir - Blodgett monolayers are shorter due to molecules inclination. Influence of the X-ray beams on the LB film structure transformation are investigated. We found that X-ray irradiation did not change structure of the film. Disappearing of the one bilayer on the film/air border and the film roughness increasing are noticed.
\end{abstract}

Molecular devices based on Langmuir - Blodgett (LB) technology [1,2] are widely used in various fields of reasearch and applications including microelectronics, lithography, sensors, biotechnology [3]. Physical properties of LB films strongly depend on their structure. It is well known that the structure of the layers in the bottom and in the top of a film, i.e. interfacial parts of a film, in general, differs significantly from the structure in the "bulk".

The essential interest of this work is to focuss on the investigation of differences in the structure of interfacial and bulk monolayers. For this purpose LB films of cadmium stearate $\left(\mathrm{C}_{18} \mathrm{H}_{35} \mathrm{O}_{2}\right)_{2} \mathrm{Cd}$ and cadmium behenate $\left(\mathrm{C}_{22} \mathrm{H}_{43} \mathrm{O}_{2}\right)_{2} \mathrm{Cd}$ deposited on a Si-substrate and consisting of 10 bilayers were studied using $\mathrm{X}$-ray reflectometry technique [4,5]. This method allows to study a structure (concentration profile) multilayer system in the $\mathbf{Z}$ direction which is normal to the surface of the film. This density profile function $\rho(z)$ presents an averaged value (for the whole $X Y$ plane) for each $\mathbf{Z}_{\mathbf{i}}$ point. A small number of bilayers are chosen as in this case scattering from interface layers is fairly distinct in compare to the background of general scattering.

Reflectometric measurements were carried out on a modified AMUR-2 small-angle X-ray diffractometer, which has been constructed at the Institute of Crystallography, Russian Academy of Sciences [6]. The X-ray source was a fine focus X-ray tube with a copper anode. CuK $\lambda 1$ radiation isolated by a Ge single crystal monochromator was used for reflectivity measurements.

For the analysis of the reflectometry data a modelling technique was used. According to this technique the film was mentally divided on a set of stacked homogeneous sublayers. Each sublayer $\mathbf{i}$ $(i=1,2, \ldots M)$ is characterised by its thickness $d_{i}$, electron density $\rho_{i}$ and roughness $\sigma_{i}$ of the border between two neighbour sublayers. In fact instead of electron density we use coefficients of refractive index $\mathrm{N}=1-\delta$ - $\mathrm{i}^{*} \beta$, where $\delta$ is proportional to $\rho$ [7]. The set of values $\mathrm{d}_{\mathrm{i}}, \rho_{\mathrm{i}}, \sigma_{\mathrm{i}}(\mathrm{i}=1,2, . . \mathrm{M})$ gives the electron density profile $\rho(\mathbf{z})$ along the direction of the $\mathrm{Z}$ axis. Values of the mentioned parameters are the target in the procedure of fitting the scattering intensity calculated from the model to its measured value. The fitting program is based on the Parratt algorithm of reflectivity calculations [7]. Each bilayer, which is a repeat unit of the system, is naturally divided into five sublayers. Two of them are the representations of terminal methyl groups. Two other sublayers are associated with hydrocarbon chains. The last sublayer which is located in the middle of the previous ones is connected with the location of cadmium ions.

The surface structure of the Si-wafer was studied before LB film deposition. It is found that on the surface of the $\mathrm{Si}$ - wafer the film is $15 \AA$ thick. We associate this film with a natural $\mathrm{SiO}_{2}$ layer. The characteristics of the layer (Table $1, a, b$ ) were then used during the fitting procedure of the models to experimental data.

The experimental data (dots) and scattering intensity calculated for the best model at each step (solid line) of fitting are represented on Fig.1. On the first step a model (Fig.1,a) of the LB film was built up on the what we knew of the film: 1) repeat unit length of the multilayer system $49.8 \pm 0.1 \AA$ calculated by Bragg peak position, 2) 10 repeat units were deposited, 3) total thickness of the film $515 \pm 5 \AA$ calculated from the position of interference maxima of the waves reflected from upper and lower film interface (so-called Kiessig fringes). Characteristics of the film model on this step are given in Table 1,a (Lines $1, . ., 5$ represent a structure of the repeat unit and performed 10 times.). On the second step (Fig.1,b) we add to the model a layer between $\mathrm{SiO}_{2}$ and the fist $\mathrm{LB}$ film sublayers. 
This layer which thickness and electron density were unknown at the beginning was created on the $\mathrm{Si}$ substrate to get hydrophobic properties of the substrate surface and in order to make easy deposition process of the film (to have a first layer directed towards by hydrocarbon chains to substrate). After fitting we determined characteristics of the hydrophobic layer (Table 1,b, line 6) and refined other structure parameters (Table 1,b. See only $1, \ldots, 8$ lines). To decrease the systematic discrepancy between experimental and calculated scattering intensities at the Bragg peak position, the model was improved by adding a new parameter: the roughness between each sublayer. The best agreements with experiment are reached with roughness parameter $\sigma=2.3 \AA$ (Fig. 1, c). All other parameters are the same as for the second step of fitting. Scattering intensity calculated for the third model is in a good agreement with the experimental values except for the region between the second and third Bragg peaks. Peculiarities in scattering intensity between Bragg peaks are mostly due to the scattering on that part of the film which is not involved in repeat units. Thus, we complicated our model by thickness variation of the sublayers associated with hydrocarbon chains of the uppest and lowest monolayers. In spite of the variety of the model parameters, only this model complication is justified. The fitting procedure of the forth model result in values of thickness interface monolayers (Fig. 1, d. Table 1 all lines /Lines $1, . ., 5$ which stand for repeat unit should be performed 8 times/). It turns out that this monolayers are thinner if compared with the monolayers in the film bulk. We associate decreasing of thickness of the interface monolayers with hydrocarbon chains inclination due to imperfections in the monolayer planes. Change of thickness corresponds to $35.6^{\circ}$ for the upper monolayer and $25^{\circ}$ for the lower one.

Table 1. Parameters from fit to $\left(\mathrm{C}_{18} \mathrm{H}_{3} \mathrm{O}_{2}\right)_{2} \mathrm{Cd} / \mathrm{Si}(\mathrm{CH} 3)_{2} / \mathrm{SiO}_{2} / \mathrm{Si}$ reflectivity data

a)

\begin{tabular}{||c|c|c|c|c||}
\hline Number & $\begin{array}{l}\text { Chemical } \\
\text { group }\end{array}$ & $\begin{array}{c}\text { thickness } \\
\AA\end{array}$ & $\delta, 10^{-6}$ & $\beta, 10^{-7}$ \\
\hline 1 & $\mathrm{H}$ & 0.8 & 0.7 & 0 \\
\hline 2 & $\mathrm{H}-\mathrm{C}-\mathrm{H}$ & 21.35 & 3.9 & 0 \\
\hline 3 & $\mathrm{Cd}(\mathrm{COO})_{2}$ & 5.6 & 13.0 & 5.8 \\
\hline 4 & $\mathrm{H}-\mathrm{C}-\mathrm{H}$ & 21.35 & 3.9 & 0 \\
\hline 5 & $\mathrm{H}$ & 0.8 & 0.7 & 0 \\
\hline 7 & $\mathrm{SiO}_{2}$ & 15.0 & 5.1 & 1.2 \\
\hline 8 & $\mathrm{Si}$ & --- & 8.6 & 1.7 \\
\hline
\end{tabular}

b)

\begin{tabular}{||c|c|c|c|c||}
\hline \hline Number & $\begin{array}{c}\text { Chemical } \\
\text { group }\end{array}$ & $\begin{array}{c}\text { thickness } \\
\AA\end{array}$ & $\bar{\delta}, 10^{-6}$ & $\beta, 10^{-7}$ \\
\hline & $\mathrm{H}$ & 0.8 & 0.7 & 0.1 \\
\hline & $\mathrm{H}-\mathrm{C}-\mathrm{H}$ & 17.35 & 3.6 & 0.5 \\
\hline & $\mathrm{Cd}(\mathrm{COO})_{2}$ & 5.6 & 11.0 & 1.9 \\
\hline & $\mathrm{H}-\mathrm{C}-\mathrm{H}$ & 21.35 & 3.6 & 0.5 \\
\hline & $\mathrm{H}$ & 0.8 & 0.7 & 0.1 \\
\hline 1 & $\mathrm{H}$ & 0.8 & 0.7 & 0.1 \\
\hline 2 & $\mathrm{H}-\mathrm{C}-\mathrm{H}$ & 21.35 & 3.6 & 0.5 \\
\hline 3 & $\mathrm{Cd}(\mathrm{COO})_{2}$ & 5.6 & 11.0 & 1.9 \\
\hline 4 & $\mathrm{H}-\mathrm{C}-\mathrm{H}$ & 21.35 & 3.6 & 0.5 \\
\hline 5 & $\mathrm{H}$ & 0.8 & 0.7 & 0.1 \\
\hline & $\mathrm{H}$ & 0.8 & 0.7 & 0.1 \\
\hline & $\mathrm{H}-\mathrm{C}-\mathrm{H}$ & 21.35 & 3.6 & 0.5 \\
\hline & $\mathrm{Cd}(\mathrm{COO})_{2}$ & 5.6 & 11.0 & 1.9 \\
\hline & $\mathrm{H}-\mathrm{C}-\mathrm{H}$ & 19.35 & 3.6 & 0.5 \\
\hline & $\mathrm{H}$ & 0.8 & 0.7 & 0.1 \\
\hline 6 & $\mathrm{Si}(\mathrm{CH} 3)_{2}$ & 8.0 & 4.6 & 0.5 \\
\hline 7 & $\mathrm{SiO} 2$ & 15.0 & 5.1 & 1.2 \\
\hline 8 & $\mathrm{Si}$ & --- & 8.6 & 1.7 \\
\hline & \multicolumn{5}{|l}{} \\
\hline
\end{tabular}




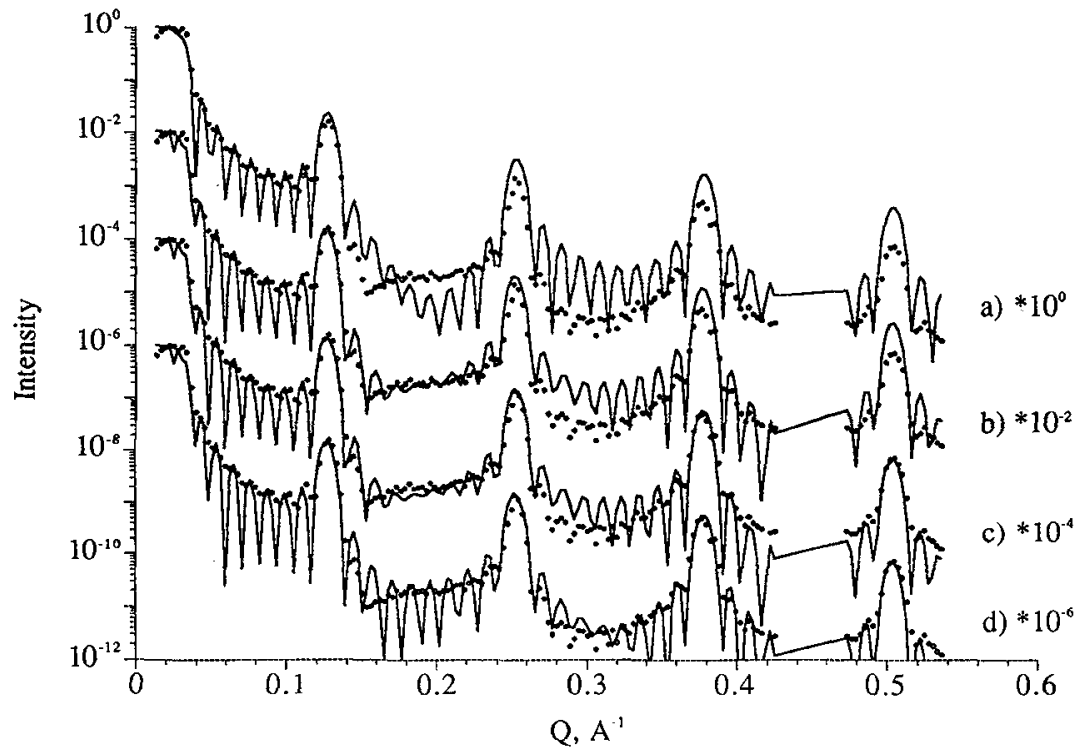

Figure 1. Sequence of steps in fitting of the reflectivity data for LB film of cadmium stearate. Numbers near letters show order of magnitude on which experimental and calculated data are shifted from their true position.

As we did not have enough statistics, we could not specify parameters of electron density for monolayers lying on the borders substrate/LB-film and LB-film/air. Statistics can be increased a using synchrotron source of X-rays. To simulate influence of synchrotron X-ray irradiation on LB film structure, we irradiated a 10 bilayer $\mathrm{LB}$ film of cadmium behenate $\left(\mathrm{C}_{22} \mathrm{H}_{43} \mathrm{O}_{2}\right)_{2} \mathrm{Cd}$ using "white" spectrum of the X-rays beam produced by usual tube with a copper anode. We noticed the LB film structure changes after irradiation. Three X-ray reflectivity measurements were carried out to separate influence on the structure changes 1) of the ionised air induced by X-ray and 2) direct influence of the X-ray beam. The results of the measurements are summarised in Fig.2. We will go on precising structure informations, which will be published elsewhere. We will describe only qualitative side structure transformations during X-ray irradiation. Just after preparation a 10 bilayers LB film has exactly deposited number of bilayers Fig.2,a. One can see it from the number of Kiessig fringes between the second and the third Bragg peak. (This number is 8 and equal $\mathbf{k - 2}$, where $\mathbf{k}$ is the number of bilayers.) Relative intensities of the Bragg peaks in its ordinal sequence are 1.0, 0.119, 0.084 . The repeat unit distance is $59.8 \AA$. The position of the Bragg peaks, number of bilayers (film thickness) and structure of repeat unit did not change after keeping the same film in ionised air Fig.2,b. The film was protected from direct X-ray beam. Relative intensity of the Bragg peaks are $1.0,0.085,0.037$. The changes in Bragg peaks intensity correspond to the increase of relative roughness to $2.9 \AA$. Finally the LB film was brought in contact with direct X-ray beam during 17 hours (Fig.2,c). The position of the Bragg peaks and repeat unit structure did not change again. But the intensity of the Bragg peaks significantly changed $(1.0,0.065,0.011)$. This result can be explained by increasing the roughness up to $4.8 \AA$ by comparison of the roughness for the initial LB film stage. A more important transformation happened with the thickness of the film. One can see now only 7 Kiessig fringes between second and third Bragg peaks instead of 8 at the beginning. The structure model after fitting procedure shows that instead of the uppest monolayer with thickness $59.8 \AA$ there is only a $4.0 \AA$ thickness film with a very weak electron density. 


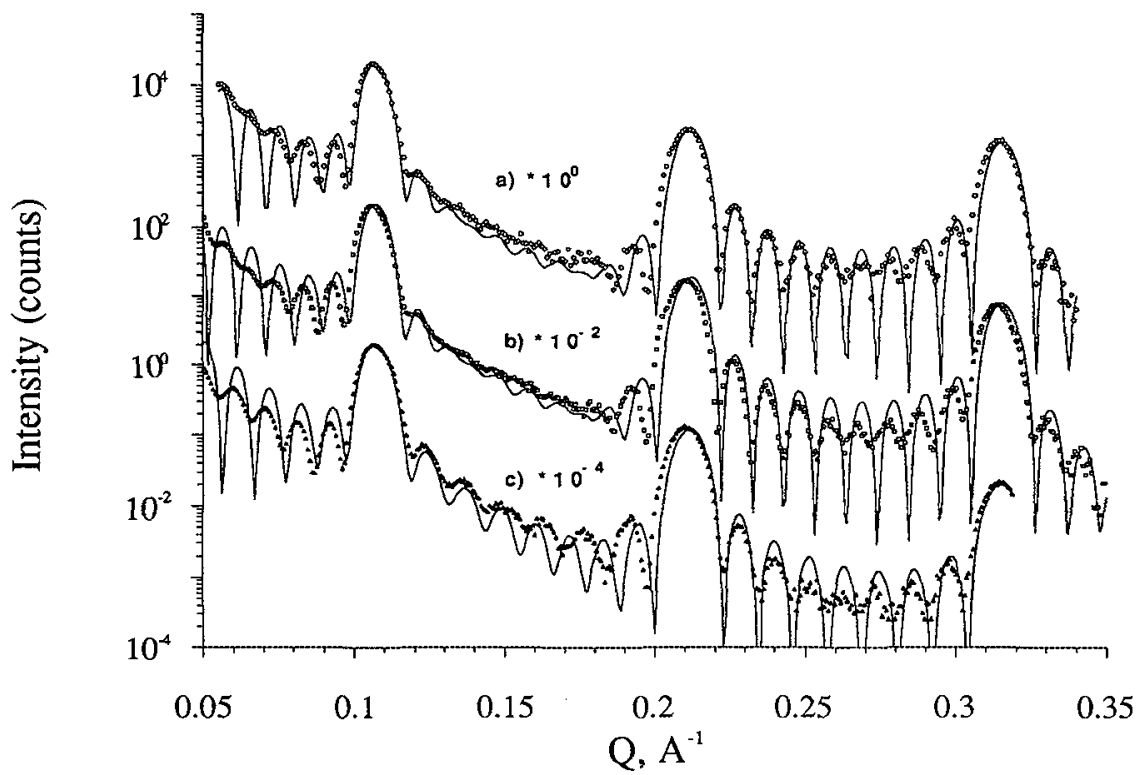

Figure 2. Evolution of reflectivity scattering from cadmium behenate LB film versus different influence of X-ray irradiation: a) LB film just after preparation

b) after 18 hours keeping in ionised air induced by $X$-rays

c) after 17 hours keeping in direct $X$-ray beam $(30 \mathrm{kV}, 30 \mathrm{~mA})$

We found that monolayers lying on the above mentioned border substrate/LB-film and LBfilm/air had a different structure by comparison with the monolayer one in the bulk of the film. In particular, the monolayers are shorter respectively to $4 \AA$ and $2 \AA$ correspondingly. To summarise the main results on structural changes of the 10 bilayer LB film of cadmium behenate during its irradiation using "white" spectrum of the X-rays shows 1) increasing of the LB film roughness, 2) quasi complete disappearing of the one bilayer on the film/air border, 3). LB film irradiation did not cause a structure change of the repeat unit.

\section{REFERENCES}

1. BLODGETT K.B., LANGMUIR I., Phys.Rev. 51 (1937) 964.

2. ROBERTS G.G., Adv. Phys., 34 (1985) 475.

3. PETTI M.C., Thin Solid Films, 210/211 (1992) 417 (and references).

4. PENFOLD J., THOMAS R.K., J.Phys, C2 (1990) 1369.

5. PERSHAN P.S., BRASLAU A., WEISS A.M., ALS-NIELSEN J., Phys.Rev., A35 (1987) 4800.

6. KONOVALOV O.V., Sov.Phys. Crystallogr. (USA), 37 (1992) 101.

7. PARRATT L.G., Phys,Rev., B95 (1954) 359 